\title{
Festina Lente: Evidences for Fast and Slow Learning Processes and a Role for Sleep in Human Motor Skill Learning
}

\author{
Pierre Maquet, ${ }^{1}$ Steven Laureys, Fabien Perrin, Perrine Ruby, Gwénaëlle Melchior, \\ Mélanie Boly, Tahn Dang Vu, Martin Desseilles, and Philippe Peigneux
}

Cyclotron Research Centre, University of Liège, Belgium

In our everyday life, a wide range of motor, perceptual, and cognitive abilities are gradually and implicitly acquired through our continuous interaction with the environment, a process referred to as skill learning. Converging data indicate that skill learning is a multiple step process that cannot be reduced to the acquisition episode only. In the initial step, while the subject is practicing the task, the performance asymptotically improves with continued practice. This corresponds to a process coined as fast learning by Karni and coworkers (Karni and Sagi 1993; Karni et al. 1995). Remarkably, however, the initially formed memory trace apparently continues to be reprocessed after the training has ended. Consequently, when tested at a later date, up to several days to weeks later, the performance to the task is markedly improved even without any intervening training sessions. This so-called slow component of learning has been observed in humans for both perceptual and motor skill learning (Karni and Sagi 1993; Karni et al. 1995), and seems to depend critically on sleep rather than simply on time or initial practice (Maquet 2001; Peigneux et al. 2001). In this issue, Walker and colleagues investigate the interplay between the fast and slow components of learning.

In the domain of motor skill learning, the finger tapping task (FTT), or its variant the finger opposition task, has been a useful model to characterize the fast and slow components of the learning process as well as the respective effects of time, practice, and sleep on the latter. In this task, the subjects are asked to repeat a five-element sequence of finger movements with the nondominant hand, as fast and as accurately as possible (Fig. 1C). The performance measure consists of the number of correctly repeated sequences in a given time (usually $30 \mathrm{sec}$ ). Whereas a moderate, albeit significant, increase in performance is reported during the training session and between training episodes on the same day, a much larger gain in performance is systematically observed overnight (Fischer et al. 2002; Walker et al. 2002; Walker et al. 2003; Fig.1A,B). This suggests that sleep is a major factor underlying the overnight gain in performance. Accordingly, it was shown that slow learning is significantly enhanced when participants are allowed to sleep between the training and the retest sessions (Fischer et al. 2002). The large improvement in performance is observed both after night time and day time sleep, ruling out a potential circadian influence on slow learning (Fischer et al. 2002).

The exact influence of sleep on the slow component of skill learning is still unclear. For some tasks, (FTT: Fischer et al. 2002; pursuit task: Maquet et al. 2003), a small gain in performance persists despite a total sleep deprivation during the first posttraining night. For other tasks (visual texture discrimination task;

'Corresponding author.

E-MAIL Maquet@pet.crc.ulg.ac.be; FAX 32-4366-2946.

Article and publication are at http://www.learnmem.org/cgi/doi/10.1101/ Im.64303.
Stickgold et al. 2000a), sleep seems a prerequisite for any significant performance improvement. Likewise, the respective role of the various sleep stages in skill learning is still unclear. Early results suggested that perceptual (visual) learning was sensitive to rapid eye movement (REM) sleep deprivation (Karni et al. 1994). Subsequent work emphasized that a maximal improvement in performance was observed after the succession of a large amount of SWS early in the night and REM sleep late in the night, raising the possibility of a double-step process in memory consolidation (Gais et al. 2000; Stickgold et al. 2000a,b). For motor skill learning, data are still too fragmentary to reach any definite conclusion. The improvement in performance has been reported to be related linearly to the time spent in REM sleep (Fischer et al. 2002) or in stage- 2 non-REM sleep late in the night (Walker et al. 2002). Future research should sort out this issue. In any case, the gain in performance after motor-skill learning is robust and long lasting. It is still there after two nights of sleep (Fischer et al. 2002) and as shown by Walker and colleagues in this issue, might still slightly increase after the third post training night. The combined effect of daily motor practice and regular sleep might eventually lead to dramatic improvement in performance that plateaus after 2-3 wk (Karni et al. 1995; Fig. 1C).

In this issue, Walker and colleagues now focus on the relationships between the fast (within session) and the slow (between session, overnight) components of learning (Fig. 1A,B). Do these components evolve independently or not? No correlation between the within-session improvement and the overnight gain in performance was observed, suggesting statistical independence. This might indicate that fast and slow-learning phases rely on independent cellular mechanisms. Furthermore, they observe a nearly identical overnight improvement, irrespective of the amount of practice prior to sleep. Although subjects extensively trained reached a higher level of performance during practice than subjects with a limited amount of practice, the overnight gain was nearly identical (Fig.1B). This suggests that sleep-dependent slow learning is independent of the evolution of the fast component during prior practice. Still, this does not diminish the importance of the fast component of learning in order to initiate sleep-dependent slow learning processes, as suggested by Hauptmann and Karni (2002) in the case of a priming task. In this latter task, the fast (within-session) learning component has to be exhausted before any slow (between-day) learning can reliably be detected. As Walker and colleagues (this issue) used a pretty intensive training $(4 \times 1230$-sec blocks in group $1 ; 2 \times 1230$-sec blocks in group 3 ), the fast learning component might have been exhausted on the first experimental day. Therefore, no significant within-session improvement occurs during subsequent sessions (on day 2), and the gain in performance is mainly accounted for by the slow sleep-dependent overnight component.

Accordingly, at the systems level, it is known that there is a 

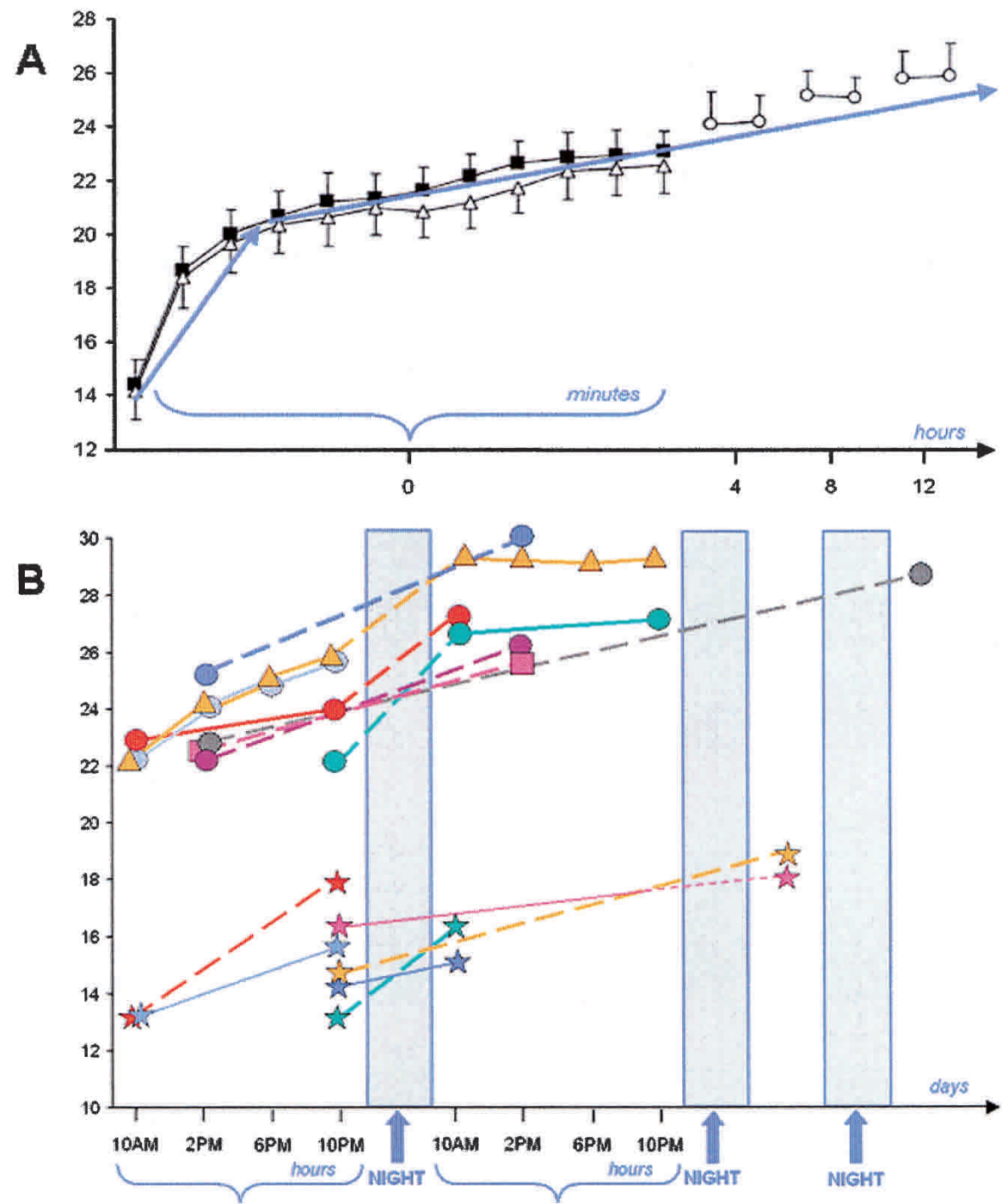

Figure 1 Fast and slow components of motor-skill learning, from minutes to weeks. $(A)$ Fast, within-session component of motor sequence learning. Performance rapidly improves over the first three blocks (30 sec each), then slowly evolves though practice. Four-hour intervals between sessions on the same day did not improve performance more than expected by mere practice (adapted from Walker et al. 2002). (B) Fast and slow components of motorsequence learning. Broken lines between two symbols represent intervals of sleep, straight lines represent intervals of wakefulness. (Stars) Performance measures for groups from the Fischer et al. (2002) study, trained at $10 \mathrm{AM}$ or $10 \mathrm{PM}$, and retested after an interval of $12 \mathrm{~h}$ of sleep or wakefulness. Subjects tested $48 \mathrm{~h}$ later slept, or stayed awake during the first posttraining night. Performance is systematically higher in the sleep than in the wakefulness condition. (Triangles) Performance measures for subjects trained four times at 4-h intervals during day 1 and during day 2 in the Walker study. Performance improves across repeated sessions during day 1 , but not during day 2 , suggesting saturation of the fast component of learning. The higher amplitude of the gain in performance between last session in day 1 and first session in day 2, filled with a sleep interval, indicates off-line reprocessing of the motor sequence during sleep, eventually leading to improved performance on the next day. (Circles) Performance measures for groups from the Walker et al. (2002) study. Subjects trained four times at 4-h intervals during the same day showed slight between-sessions improvement (light gray). Performance gain between sessions performed at 12-h intervals was significantly higher after a night (sleep) interval than after a day (wake) interval, irrespective of the amount of training accumulated during the same period of wakefulness (red and green circles). Performance gain after $72 \mathrm{~h}$ (3 nights, dark gray circles) tends to be higher than after one night only. (Squares) Performance measures for one group from the Karni et al. (1998) study, retested after a 24-h interval (including sleep) (C) Finger tapping task (FTT). Subjects are asked to reproduce a repetitive sequence of finger-thumb opposition movements (Karni et al. 1995; Fischer et al. 2002) or to press a sequence of key presses on a computer keyboard with the four fingers (Walker et al. 2002, 2003, this issue). Performance at each block is measured as the number of correct sequences produced in $30 \mathrm{sec}$. (D) Slow component of motor sequence learning. Subjects had 10-20 min of daily practice to the FTT during 5 wk. Performance dramatically improves across days to reach an asymptote after $2-3 \mathrm{wk}$, with a maximal performance of 50 sequences per $30 \mathrm{sec}$.

shift of activation from the cerebellar cortex to the dentate nucleus during early learning of a motor sequence, and from a cerebellar-cortical to a striatal-cortical network with extended practice on the same day (Doyon et al. 2002), followed further by the experience-dependent reactivation of the cortico-striatal network during REM sleep (Maquet et al. 2000; Peigneux et al. 2003). These data collectively suggest an early reorganization of the cor- tical network subtending motor-sequence learning across repeated practice during training, then its consolidation and optimization through off-line practice during the subsequent night. Moreover, the reactivation of cortical areas during REM sleep is proportional to the level of performance achieved at the end of the training session to the procedural serial learning task (SRTT, Peigneux et al. 2003). In this case, one would argue that the

\section{Learning \& Memory}

www.learnmem.org 
cellular processes underlying the fast-learning stage modulate the slow learning processes that take place during sleep, although the within- and between-sessions components may statistically show independence. Once again, the exact relationships between fast and slow learning processes will have to be better characterized by further research.

Finally, the cellular mechanisms underlying the fast and slow components in skill learning are still unknown in humans. As rightly pointed out by Walker, their results are in line with studies of motor learning in rodents. Intrinsic horizontal connections are strong candidate substrates for motor cortex remapping after skill learning (Sanes and Donoghue 2000). Ex vivo studies of primary motor cortex in rats demonstrate that motor skill learning is first accompanied by increased efficacy in intracortical horizontal connections (Rioult-Pedotti et al. 1998), most probably through the activation of long-term potentiation (LTP; Rioult-Pedotti et al. 2000). Admittedly, these results were obtained after a 5-d training in rats, but data obtained in humans suggest similar processes after a single day of training (Butefisch et al. 2000). Consequently, they might underpin the fast-learning phase. The slow-learning phase probably requires gene transcription and protein synthesis (Abel and Lattal 2001; Graves et al. 2001). Evidence for gene transcription during posttraining sleep is available for hippocampus-dependent memory in rats (Ribeiro et al. 1999, 2002). Further research should characterize the cascade of molecular events that accompany motor-skill learning in rodent motor cortex.

\section{REFERENCES}

Abel, T. and Lattal, K.M. 2001. Molecular mechanisms of memory acquisition, consolidation and retrieval. Curr. Opin. Neurobiol. 11: $180-187$

Butefisch, C.M., Davis, B.C., Wise, S.P., Sawaki, L., Kopylev, L., Classen, J., and Cohen, L.G. 2000. Mechanisms of use-dependent plasticity in the human motor cortex. Proc. Natl. Acad. Sci. 97: 3661-3665.

Doyon, J., Song, A.W., Karni, A., Lalonde, F., Adams, M.M., and Ungerleider, L.G. 2002. Experience-dependent changes in cerebellar contributions to motor sequence learning. Proc. Natl. Acad. Sci. 99: 1017-1022.

Fischer, S., Hallschmid, M., Elsner, A.L., and Born, J. 2002. Sleep forms memory for finger skills. Proc. Natl. Acad. Sci. 99: 11987-11991.

Gais, S., Plihal, W., Wagner, U., and Born, J. 2000. Early sleep triggers memory for early visual discrimination skills. Nat. Neurosci. 3: $1335-1339$.

Graves, L., Pack, A., and Abel, T. 2001. Sleep and memory: A molecular perspective. Trends Neurosci. 24: 237-243.
Hauptmann, B. and Karni, A. 2002. From primed to learn: The saturation of repetition priming and the induction of long-term memory. Brain Res. Cogn. Brain Res. 13: 313-322.

Karni, A. and Sagi, D. 1993. The time course of learning a visual skill. Nature 365: 250-252.

Karni, A., Tanne, D., Rubenstein, B.S., Askenasy, J.J., and Sagi, D. 1994. Dependence on REM sleep of overnight improvement of a perceptual skill. Science 265: 679-682.

Karni, A., Meyer, G., Jezzard, P., Adams, M.M., Turner, R., and Ungerleider, L.G. 1995. Functional MRI evidence for adult motor cortex plasticity during motor skill learning. Nature 377: 155-158.

Maquet, P. 2001. The role of sleep in learning and memory. Science 294: $1048-1052$.

Maquet, P., Laureys, S., Peigneux, P., Fuchs, S., Petiau, C., Phillips, C., Aerts, J., Del Fiore, G., Degueldre, C., Meulemans, T., et al. 2000. Experience-dependent changes in cerebral activation during human REM sleep. Nat. Neurosci. 3: 831-836.

Maquet, P., Schwartz, S., Passingham, R., and Frith, C. 2003. Sleep-related consolidation of a visuomotor skill: Brain mechanisms as assessed by functional magnetic resonance imaging. J. Neurosci. 23: $1432-1440$.

Peigneux, P., Laureys, S., Delbeuck, X., and Maquet, P. 2001. Sleeping brain, learning brain. The role of sleep for memory system. Neuroreport 12: A111-A124.

Peigneux, P., Laureys, L., Fuchs, S., Collette, F., Delbeuck, X., Phillips, C., Aerts, J., Del Fiore, G., Degueldre, C., Luxen, A., et al. 2003. Learned material content and acquisition level modulate cerebral reactivation during post-training rem sleep. NeuroImage (in press).

Ribeiro, S., Goyal, V., Mello, C.V., and Pavlides, C. 1999. Brain gene expression during REM sleep depends on prior waking experience. Learn. Mem. 6: 500-508.

Ribeiro, S., Mello, C.V., Velho, T., Gardner, T.J., Jarvis, E.D., and Pavlides, C. 2002. Induction of hippocampal long-term potentiation during waking leads to increased extrahippocampal zif-268 expression during ensuing rapid-eye-movement sleep. J. Neurosci. 22: 10914-10923.

Rioult-Pedotti, M.S., Friedman, D., Hess, G., and Donoghue, J.P. 1998. Strengthening of horizontal cortical connections following skill learning. Nat. Neurosci. 1: 230-234.

Rioult-Pedotti, M.S., Friedman, D., and Donoghue, J.P. 2000. Learning-induced LTP in neocortex. Science 290: 533-536.

Sanes, J.N. and Donoghue, J.P. 2000. Plasticity and primary motor cortex. Annu. Rev. Neurosci. 23: 393-415.

Stickgold, R., James, L., and Hobson, J.A. 2000a. Visual discrimination learning requires sleep after training. Nat. Neurosci. 3: 1237-1238.

Stickgold, R., Whidbee, D., Schirmer, B., Patel, V., and Hobson, J.A. 2000b. Visual discrimination task improvement: A multi-step process occurring during sleep. J. Cogn. Neurosci. 12: 246-254.

Walker, M.P., Brakefield, T., Morgan, A., Hobson, J.A., and Stickgold, R. 2002. Practice with sleep makes perfect: Sleep-dependent motor skill learning. Neuron 35: 205-211.

Walker, M.P., Brakefield, T., Seidman, J., Morgan, A., Hobson, J.A., and Stickgold, R. 2003. Sleep and the Time Course of Motor Skill Learning. Learn. Mem. (this issue). 


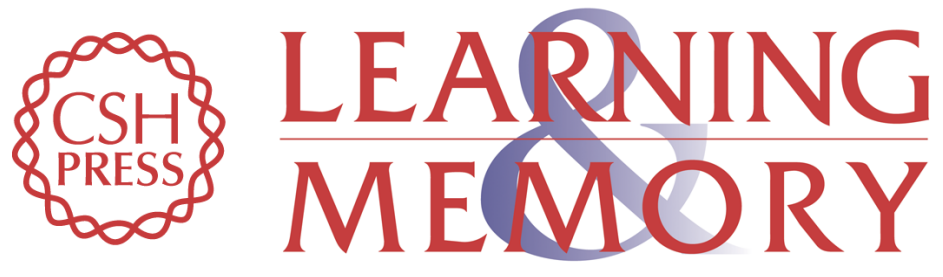

\section{Festina Lente: Evidences for Fast and Slow Learning Processes and a Role for Sleep in Human Motor Skill Learning}

Pierre Maquet, Steven Laureys, Fabien Perrin, et al.

Learn. Mem. 2003, 10:

Access the most recent version at doi:10.1101/lm.64303

References This article cites 22 articles, 9 of which can be accessed free at: http://learnmem.cshlp.org/content/10/4/237.full.html\#ref-list-1

License

Email Alerting

Receive free email alerts when new articles cite this article - sign up in the box at the Service top right corner of the article or click here. 